\title{
Experience with Developing a Room to Meet the Requirements of Joint Australian / New Zealand Standard 1270
}

\author{
Ben Scott and John Pearse ${ }^{\mathrm{a}}$ \\ ${ }^{a}$ University of Canterbury, Private Bag 4800, Christchurch 8140, New Zealand
}

\begin{abstract}
Hearing protectors are used as a "last line of defence" to protect people in high noise exposure environments from noise induced hearing loss. The assessment of hearing protector performance has been standardized to ensure a minimum level of performance for the end user. In New Zealand the standard AS/NZS 1270 specifies a REAT based test method to rate a hearing protector's performance. The rating is used to calculate appropriate exposure times for end users. This paper describes the modification of an existing audiology booth, to meet the sound field requirements specified in AS/NZS 1270. Current status of the facility will be reported; followed by a general discussion on future uses of the facility and related projects at the University of Canterbury.
\end{abstract}

Keywords: Hearing Protectors, AS/NZS 1270.

PACS: 43.50

\section{INTRODUCTION}

Hearing protection is often the only practical means of mitigating the effects of noise-induced hearing loss $\left(\right.$ NIHL) ${ }^{(1,2)}$. In New Zealand, NIHL is prevalent ${ }^{(3)}$, however there is also a lack of research and publications that address the issue ${ }^{(3)}$.

Facilities are being developed at the University of Canterbury to support studies of NIHL in New Zealand including the development of a room to conduct real ear attenuation at threshold (REAT) testing in accordance with AS/NZS $1270{ }^{(4)}$. This paper documents the progress to date on the room development as well as a discussion of other on-going projects related to hearing protection at the University of Canterbury.

\section{BACKGROUND}

REAT testing is recognised as providing the best real-world representation of a hearing protector's performance from laboratory measurements ${ }^{(5)}$. The basis of REAT testing is measuring the difference between occluded and unoccluded hearing thresholds for a representative population ${ }^{(5)}$. Seven $1 / 3$ octave bands of filtered pink noise centred on octave band frequencies of $125,250,500,1000,2000,4000$ and $8000 \mathrm{~Hz}$ are used as test signals ${ }^{(4)}$. REAT test methods have been standardised in ANSI S12.6 ${ }^{(6)}$, ISO 4869-1 ${ }^{(7)}$, ISO 4869-5 ${ }^{(8)}$ and AS/NZS $1270^{(4)}$. AS/NZS 1270 details the construction, performance and testing requirements for rated hearing protectors used in Australia and New Zealand. The four most demanding physical requirements of AS/NZS 1270 were found to be:

- Background noise: Maximum allowable sound pressure levels are given in FIGURE 6.

- Reverberation time: Reverberation time shall not exceed 1.6s for each test signal frequency band (FIGURE 7).

- Uniformity: The difference in sound pressure level at discrete points around the head (FIGURE 4) must satisfy $-2.5 \mathrm{~dB}<\left(\mathrm{SPL}_{\mathrm{POSITION}}-\mathrm{SPL}\right.$ REF $)<+2.5 \mathrm{~dB}$. In addition the difference between left and right positions is to be no larger than $3 \mathrm{~dB}$.

- Directionality: The sound pressure level, measured by a directional microphone when rotated $360^{\circ}$ in each of three orthogonal planes (FIGURE 5), must not exceed a maximum variation (TABLE 3) determined by experiment in an anechoic room. 


\section{ROOM DEVELOPMENT}

It was not feasible to construct a dedicated room so existing facilities were surveyed. A double walled audiology booth met background noise requirements except for the $1 / 3$ octave band centred on $100 \mathrm{~Hz}$ (FIGURE 6). Furthermore the booth had a tidy presentation, making it the most suitable place available to conduct subjective testing.

The room's volume of $17.8 \mathrm{~m}^{3}$ was initially thought to be too small considering typical reverberation room dimensions however published literature ${ }^{(9,10)}$ and preliminary testing suggested that the identified room could meet AS/NZS 1270's requirements.

The room was first tested with no modifications; the walls and roof were lined with a perforated metal sheet covering an unidentified absorptive material. The floor was carpeted. The number of speakers (up to eight) and their location was varied, however no combinations were found to pass AS/NZS 1270's requirements, nor were there any discernible patterns observed in the measurements.

A step by step method was proposed to improve the room's diffusivity. The first step was to reline the walls, roof and floor with $18 \mathrm{~mm}$ medium-density fibreboard (MDF) to improve the reflectivity of the interior surfaces. With the relined interior surfaces, and speaker positions indicated in FIGURE 1, the room was found to satisfy uniformity, directionality and reverberation time requirements whilst maintaining relatively even sound pressure level across the frequency range. Subsequent steps to further improve the sound field by the addition of diffusing elements and wall surface treatments, using ${ }^{(11)}$ as guidance, have not been carried out to date.

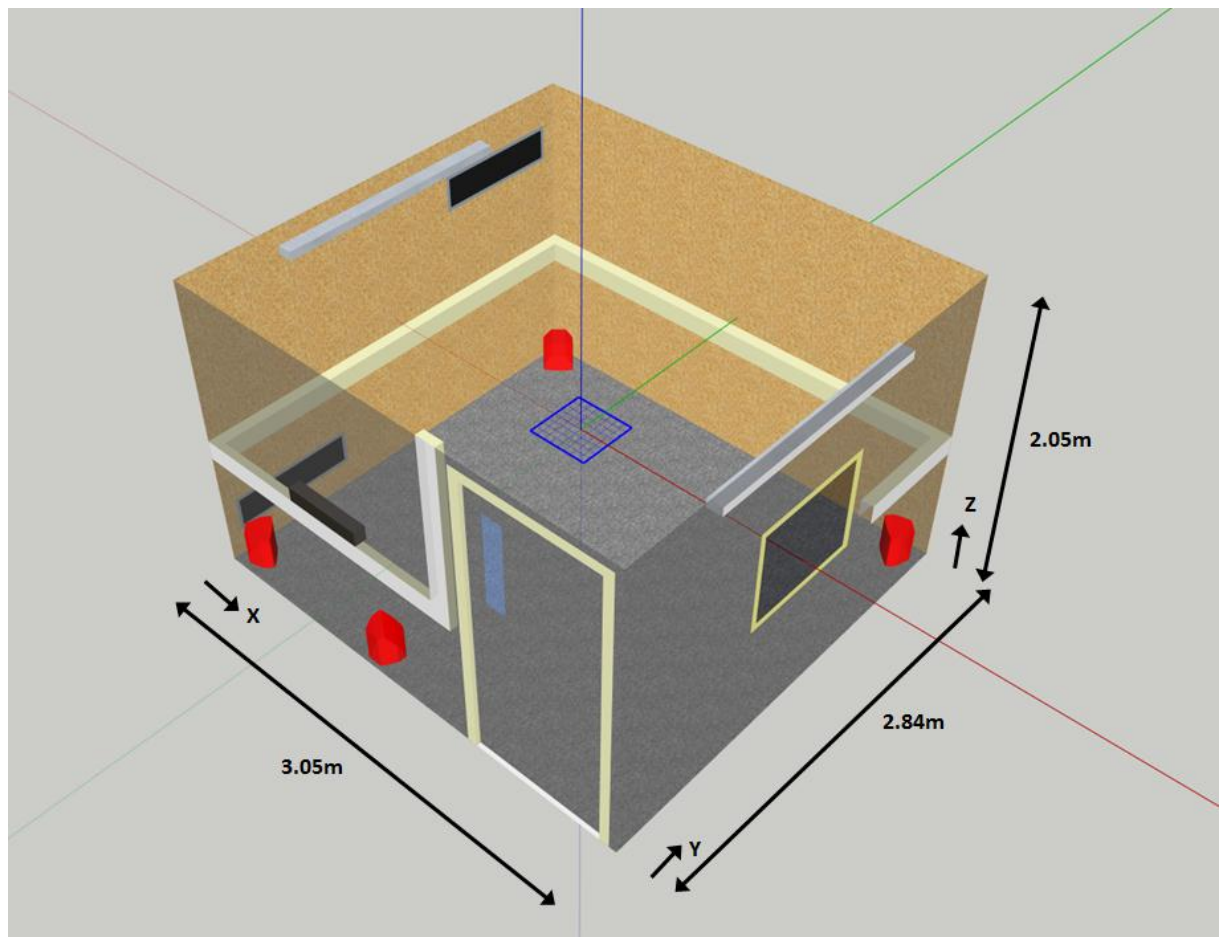

FIGURE 1: Model of the audiology booth showing one horizontal measurement plane (blue grid) and co-ordinates used in 3D sound pressure level measurements. Speaker locations (red) are also included.

\section{SETUP AND RESULTS}

Broadband pink noise was played continuously through JBL Control 25 speakers for the duration of measurements. Preliminary testing was used to choose a time weighting of $5 \mathrm{~s}$ for uniformity and directionality measurements to reduce overall experimental time; 30 s was used for background noise measurements.

AS/NZS 1270 requires uncorrelated signals to be used with one or more noise sources however no measurable difference was observed in a uniformity comparison between correlated and uncorrelated signals, thus a single signal generation source was used in the room development process, although uncorrelated signals will be used for REAT testing. 
Overall sound pressure level was maintained at the same level for each test. The spatial (uniformity) and in-plane (directionality) variation was assumed to be independent of sound pressure level.

Measurement axes and planes were also kept consistent to reduce the number of experimental variables. Position, as referred to in this paper, corresponds to [x y $\mathrm{z}$ ] co-ordinates in FIGURE 1.

\section{Uniformity}

A survey of sound pressure level at 729 points was used, instead of the standard seven point uniformity measurement (FIGURE 4), to gain further insight into the behaviour of the sound field in the room. A fixture holding nine Brüel \& Kjær 4189 microphones (FIGURE 2) was used to measure the sound pressure level in the room in a $9 \times 9$ grid (TABLE 1). 3D contour plots of sound pressure level were produced for each $1 / 3$ octave band (FIGURE 3). In addition the results could then be used to identify reference positions that satisfied the requirements of AS/NZS 1270. Positions which satisfied uniformity requirements were retested with a single Brüel \& Kjær 4942 diffuse field microphone (FIGURE 4) to confirm the results from the 729 point survey (TABLE 2).

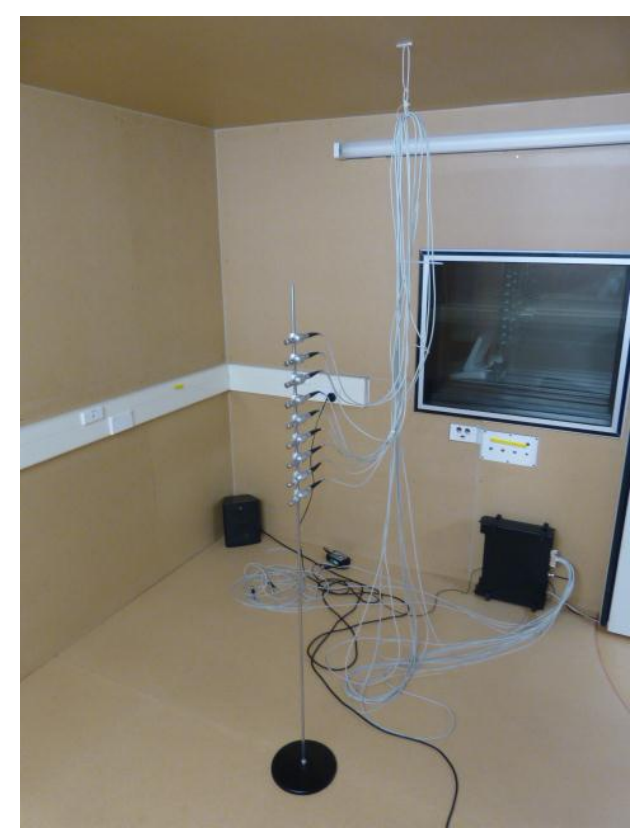

FIGURE 2: Fixture used to hold nine Brüel and Kjær 4189 microphones to conduct 729 point sound pressure level survey.

TABLE 1: Room and grid dimensions. Refer to FIGURE 1.

\begin{tabular}{cccccc}
\hline \multirow{2}{*}{ Co-ordinate } & $\begin{array}{c}\text { Dimension } \\
(\mathbf{m})\end{array}$ & $\begin{array}{c}\text { Minimum } \\
(\mathbf{m m})\end{array}$ & $\begin{array}{c}\text { Maximum } \\
(\mathbf{m m})\end{array}$ & Spacing $(\mathbf{m m})$ & \# of points \\
& & 1300 & 1700 & 50 & \\
\hline $\mathrm{X}$ & 3.05 & 1300 & 1700 & 50 & 9 \\
$\mathrm{Y}$ & 2.84 & 900 & 1300 & 50 & 9 \\
$\mathrm{Z}$ & 2.05 & & &
\end{tabular}




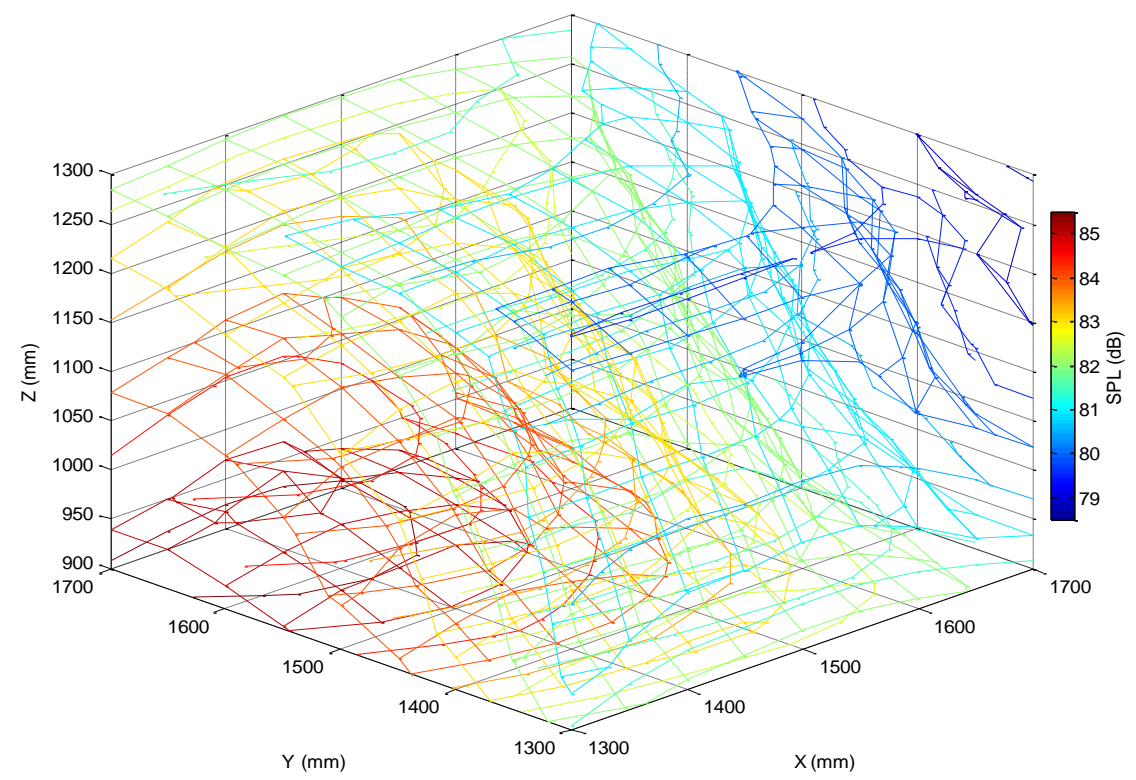

FIGURE 3: 3D contour slice plot of sound pressure level for the $1 / 3$ octave band centred on $250 \mathrm{~Hz}$.

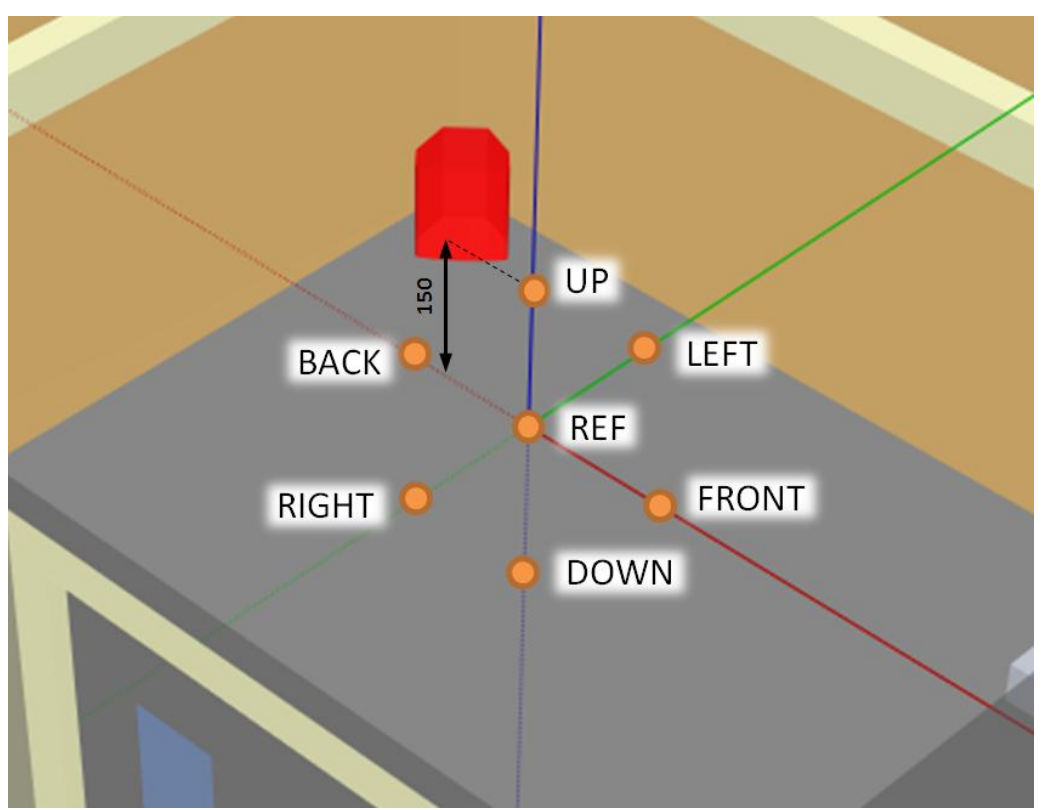

FIGURE 4: Sound field uniformity measurement positions.

TABLE 2: Uniformity results at position [1500 1500 1100].

\begin{tabular}{|c|c|c|c|c|c|c|c|c|}
\hline \multirow{2}{*}{$\mathbf{f}_{\mathrm{c}}(\mathrm{Hz})$} & \multirow{2}{*}{$\begin{array}{l}\text { SPL } L_{\text {REF }} \\
\text { (dB) }\end{array}$} & \multicolumn{6}{|c|}{ SPLPOSITION - SPL REF (dB) } & \multirow{2}{*}{$\begin{array}{c}\text { ABS(SPL } \text { LEFT }- \\
\text { SPL } \\
\text { RIGHT })\end{array}$} \\
\hline & & Front & Back & Left & Right & Up & Down & \\
\hline 125 & 87.2 & -0.1 & -0.2 & -0.6 & 0.0 & 0.8 & -0.4 & 0.6 \\
\hline 250 & 84.1 & -0.1 & -0.5 & -0.1 & -0.7 & 0.0 & -0.6 & 0.6 \\
\hline 500 & 80.4 & -1.6 & 1.3 & 1.4 & -1.6 & 1.3 & -0.3 & 2.9 \\
\hline 1000 & 76.9 & -1.1 & 0.2 & -1.0 & 1.0 & -0.6 & -0.2 & 2.0 \\
\hline 2000 & 81.8 & 0.1 & -0.3 & 0.4 & -0.1 & 0.5 & 0.5 & 0.4 \\
\hline 4000 & 79.1 & 0.0 & 0.5 & 0.3 & 0.2 & -0.1 & -0.8 & 0.0 \\
\hline 8000 & 73.6 & 0.1 & 0.5 & 0.9 & 0.2 & -0.4 & 0.0 & 0.8 \\
\hline
\end{tabular}




\section{Directionality}

The sound pressure level was measured in $20^{\circ}$ increments through $360^{\circ}$, for each of three orthogonal planes (FIGURE 5) using an OKTAVA 012 directional microphone. Overall level and microphone sensitivity were checked in a reverberation room using a Brüel \& Kjær 4942 microphone as a reference.

$20^{\circ}$ was chosen to reduce the number of measurements and because $10^{\circ}$ was the smallest increment on the rotating microphone fixture. AS/NZS 1270 requires $15^{\circ}$ increments and directionality measurements will be repeated at $10^{\circ}$ increments but have not been carried out to date. AS/NZS 1270 specifies the maximum allowable variation in sound pressure level within a plane of rotation according to the response characteristics of the microphone. Results are included in TABLE 3.

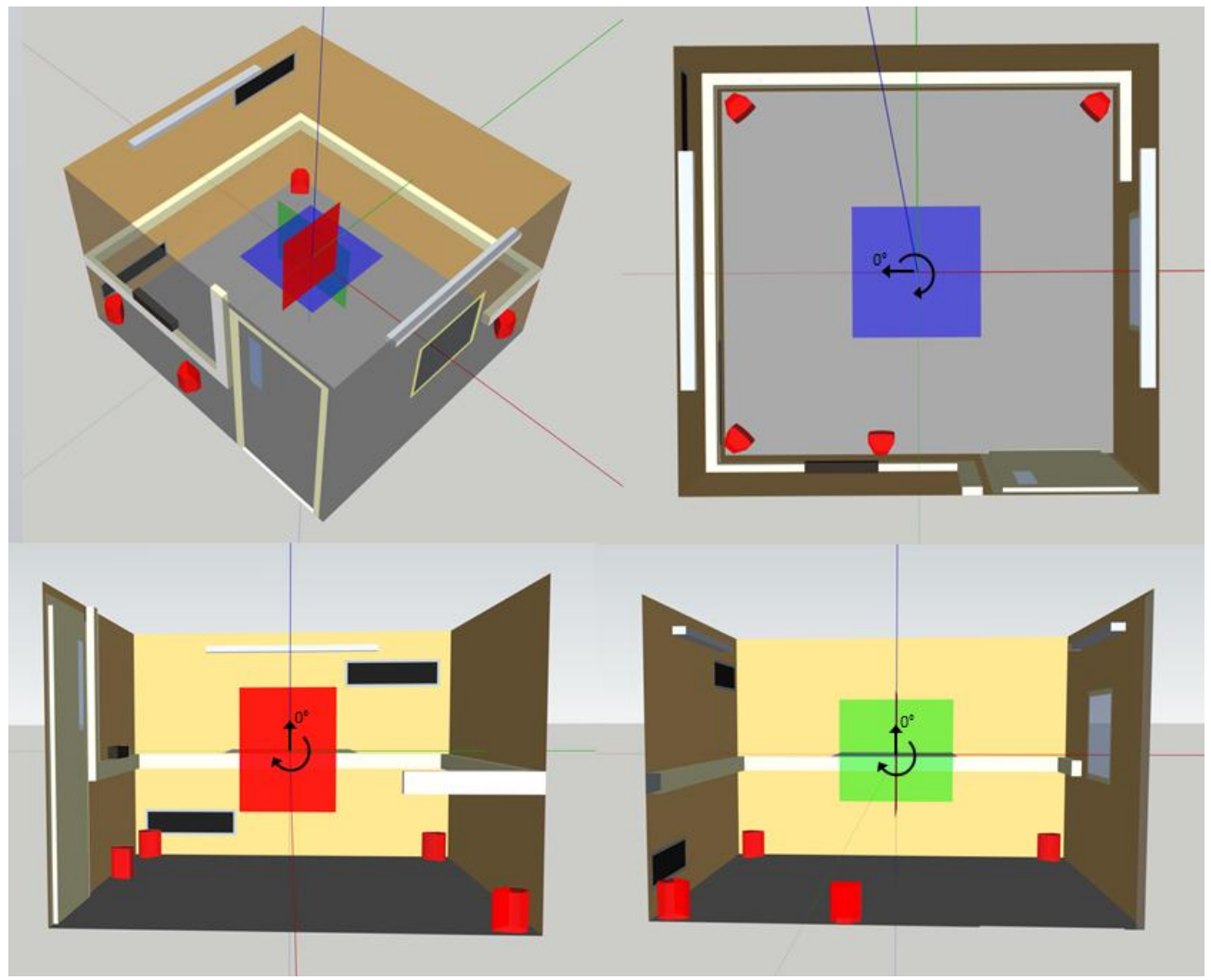

FIGURE 5: Sound field directionality's three measurement planes.

TABLE 3: Measured maximum in-plane variation at position [1500 1500 1100] for the three planes illustrated in

FIGURE 5. Maximum allowable sound pressure level was calculated in accordance with AS/NZS 1270 based on measurements in an anechoic room. AS/NZS 1270 directionality requirements are only specified for test signal frequency bands $\geq 500 \mathrm{~Hz}$.

\begin{tabular}{ccccc}
\hline \multirow{2}{*}{$\mathbf{f}_{\mathbf{c}}(\mathbf{H z})$} & $\mathbf{S P L}_{\mathbf{M A X}}$ & \multicolumn{3}{c}{$\mathbf{a b s}\left(\mathbf{S P L}_{\mathbf{M A X}}-\mathbf{S P L}_{\mathbf{M I N}}\right)(\mathbf{d B})$} \\
\cline { 3 - 5 } & & $\mathbf{1}$ & $\mathbf{2}$ & $\mathbf{3}$ \\
1000 & 3.8 & 2.6 & 2.4 & 1.9 \\
2000 & 3.8 & 2.4 & 2.3 & 2.1 \\
4000 & 3.9 & 1.1 & 1.5 & 0.6 \\
8000 & 4.9 & 0.6 & 1.2 & 2.1 \\
\end{tabular}




\section{Background noise}

Background noise was measured at position [1500 1500 1100] with a GRAS 40HF low-noise microphone in a vertical orientation. Results are included in FIGURE 6. The higher than desirable level in the $100 \mathrm{~Hz} 1 / 3$ octave band is attributed to structure borne noise from nearby building ventilation equipment. Further work is required to identify the exact noise source and transmission mechanism.

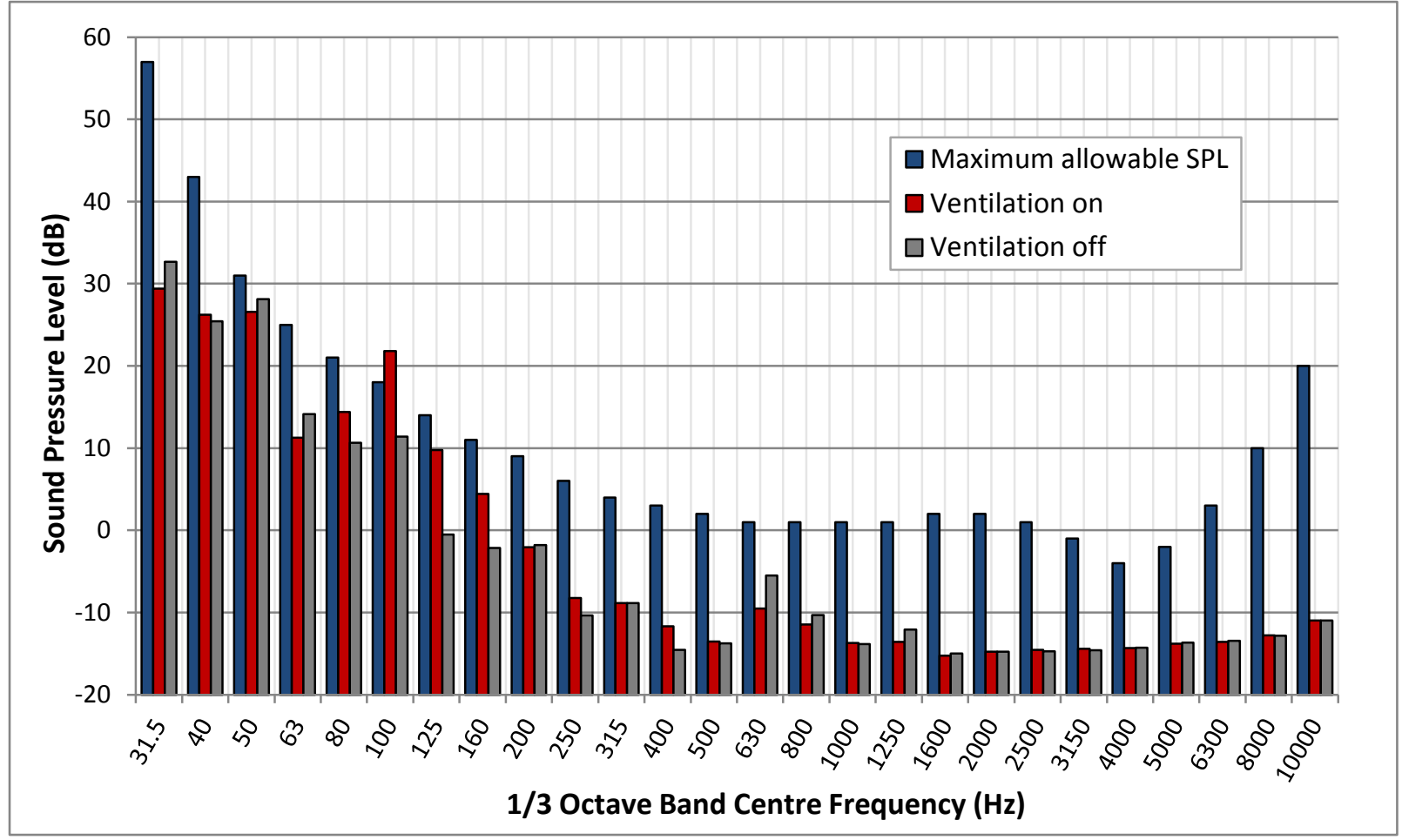

FIGURE 6: Background noise at position [1500 1500 1100] with and without nearby ventilation fan on and off. With the ventilation system off the background noise levels meet the requirements of AS/NZS 1270.

\section{Reverberation time}

Reverberation time was measured using the Brüel \& Kjær PULSE 3560-C frame with 7539 controller module and a Brüel \& Kjær 4942 diffuse field microphone in a vertical orientation. Results are included in FIGURE 7. 


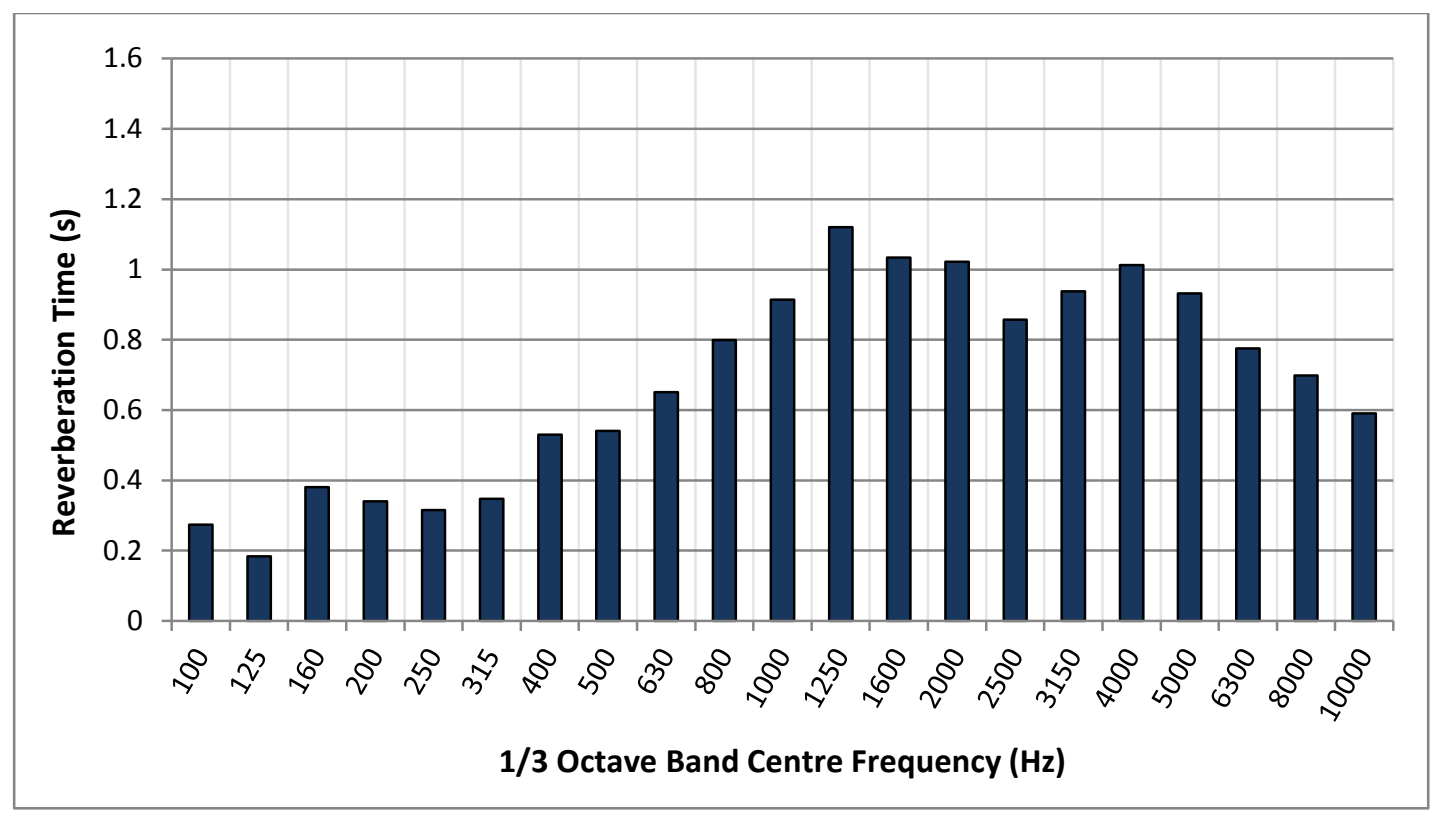

FIGURE 7: Reverberation time at position [1500 1500 1100].

\section{CURRENT STATUS}

At the time of writing the room is nearing completion with the uniformity, directionality and reverberation time satisfying the requirements of AS/NZS 1270. Further work is required to reduce the background noise in the $100 \mathrm{~Hz}$ $1 / 3$ octave band. Additional parts of AS/NZS 1270 that need to be addressed are the dynamic range and distortion requirements, however are not included in this paper.

A related studies' objective is to assess the performance of hearing protectors when being worn by subject. An additional outcome of this study would be addressing the need for published data related to New Zealand end users (3). The design and construction of a device to measure the performance of hearing protectors is currently in progress, however recent literature ${ }^{(12,13)}$ shows the design of such a device (including the testing of earplugs) has already been addressed. The current project must be reassessed.

The University of Canterbury has a Brüel \& Kjær 4128C head and torso simulator (HATS) that is used for objective testing of sand blasting helmets, earmuffs and the effect of beanie type headwear worn underneath earmuffs. The University of Canterbury has also recently acquired a GRAS 45CA test fixture to extend their testing capabilities to earplugs and calibration of audiometric headphones.

The current edition of AS/NZS $127{ }^{(4)}$ does not make allowances for level-dependent hearing protectors nor does it rate a hearing protectors effectiveness for impulsive noise. The release of ANSI S12.42 ${ }^{(14)}$ addresses some of these issues and is of considerable interest considering the advances in hearing protector technology ${ }^{(15,16)}$.

Further extensions to the 3D sound pressure level survey are planned which include:

- Extending the number of measurement positions and volume surveyed.

- Examine the effects of surface treatments and/or the addition of diffusers on the room's sound field

- Explore the effects of room treatments and diffusers on resulting REAT measurements.

\section{CONCLUSION}

The development of an audiology booth to meet the requirements of AS/NZS 1270 has been presented. Currently the facility satisfies the uniformity, directionality and reverberation time requirements. Background noise, dynamic range and distortion requirements are still being addressed.

\section{ACKNOWLEDGEMENTS}

The authors gratefully acknowledge the support of SAI Global Inc. 


\section{REFERENCES}

1. M. H. Azizi, "Occupational Noise-induced Hearing Loss", The International Journal of Occupational and Environmental Medicine (2010), 1 (3 July)

2. A. P. Kurmis and S. A. Apps, "Occupationally-acquired noise-induced hearing loss: a senseless workplace hazard", International Journal of Occupational Medicine and Environmental Health (2007), 20 (2) 127-136

3. P. R. Thorne, S. N. Ameratunga, et al., "Epidemiology of noise-induced hearing loss in New Zealand", The New Zealand Medical Journal (2008), 121 (1280) 33-44

4. Standards Australia / Standards New Zealand, AS/NZS 1270 Acoustics - Hearing Protectors (2002)

5. E. H. Berger. "Preferred methods for measuring hearing protector attenuation", INTERNOISE, Rio de Janeiro - Brazil (2005)

6. American National Standards Institute, ANSI S12.6 Methods for measuring the real-ear attenuation of hearing protectors (2008)

7. International Organization for Standardization, ISO 4869-1 Acoustics - Hearing Protectors - Part 1: Subjective method for the measurement of sound attenuation (1990)

8. International Organization for Standardization, ISO 4869-5 Acoustics -- Hearing protectors - Part 5: Method for estimation of noise reduction using fitting by inexperienced test subjects (2007)

9. C. Giguère and S. M. Abel, "A multi-purpose facility for research on hearing protection", Applied Acoustics (1990), 31 (4) 295-311

10. D. De Almeida-Agurto, S. N. Y. Gerges, and J. P. Arenas, "MIRE-IL methodology applied to measuring the noise attenuation of earmuff hearing protectors", Applied Acoustics (2011), 72 (7) 451-457

11. T. J. Schultz, "Diffusion in reverberation rooms", Journal of Sound and Vibration (1971), 16 (1) 17-28

12. E. Berger, J. Voix, R. Kieper, and C. Cocq, "Development and validation of a field microphone-in-real-ear approach for measuring hearing protector attenuation", Noise and Health (2011), 13 (51) 163

13. H. Nélisse, M. A. Gaudreau, et al., "Measurement of Hearing Protection Devices Performance in the Workplace during Full-Shift Working Operations", Annals of Occupational Hygiene (2012), 56 (2) 221-232

14. American National Standards Institute, ANSI S12.42 Method for the measurement of insertion loss of hearing protection devices in continuous or impulsive noise using microphone-in-real-ear or acoustic test fixture procedures (2010)

15. J. G. Casali, "Passive augmentations in hearing protection technology circa 2010 including flat-attenuation, passive level-dependent, passive wave resonance, passive adjustable attenuation, and adjustable-fit devices: Review of design, testing, and research", International Journal of Acoustics and Vibration (2010), 15 (4) 187

16. J. G. Casali, "Powered electronic augmentations in hearing protection technology circa 2010 including Active Noise Reduction, electronically-modulated sound transmission, and tactical communications devices: Review of design, testing, and research", International Journal of Acoustics and Vibration (2010), 15 (4) 168 